\title{
Disease Manifestation and Inflammatory Activity as Modulators of Th17/Treg Balance and RORC/FoxP3 Methylation in Systemic Sclerosis
}

\author{
Giovanni Almanzar $^{\mathrm{a}}$ Matthias Klein ${ }^{\mathrm{a}}$ Marc Schmalzing ${ }^{\mathrm{b}}$ Deborah Hilligardt ${ }^{\mathrm{a}}$ \\ Nady El Hajj ${ }^{c}$ Hermann Kneitz ${ }^{d}$ Vanessa Wild ${ }^{e}$ Andreas Rosenwald ${ }^{\mathrm{e}}$ \\ Sandrine Benoit ${ }^{d}$ Henning Hamm ${ }^{d}$ Hans-Peter Tony ${ }^{b}$ Thomas Haaf ${ }^{c}$ \\ Matthias Goebeler ${ }^{d}$ Martina Preloga \\ ${ }^{a}$ Division of Pediatric Rheumatology, and Special Immunology, University Hospital Würzburg, University of \\ Würzburg, ${ }^{b}$ Division of Rheumatology and Clinical Immunology, Department of Internal Medicine Il, 'Institute of \\ Human Genetics, dDepartment of Dermatology, Venereology, and Allergology, and e Institute of Pathology, \\ University of Würzburg, and Comprehensive Cancer Center Mainfranken, Würzburg, Germany
}

\section{Keywords}

Th17· Tregs · Methylation · Systemic sclerosis · Suppression

\begin{abstract}
Background: There is much evidence that T cells are strongly involved in the pathogenesis of localized and systemic forms of scleroderma (SSc). A dysbalance between FoxP3+ regulatory $\mathrm{CD} 4+\mathrm{T}$ cells (Tregs) and inflammatory T-helper (Th) 17 cells has been suggested. Methods: The study aimed (1) to investigate the phenotypical and functional characteristics of Th17 and Tregs in SSc patients depending on disease manifestation (limited vs. diffuse cutaneous SSc, dcSSc) and activity, and (2) the transcriptional level and methylation status of Th17- and Treg-specific transcription factors. Results: There was a concurrent accumulation of circulating peripheral IL-17-producing CCR6+ Th cells and FoxP3+ Tregs in patients with dcSSc. At the transcriptional level, Th17- and Treg-associated transcription factors were elevated in SSc. A strong association with high circulating Th17 and Tregs was seen with early, active, and severe disease presentation.
\end{abstract}

\section{KARGER}

(c) 2016 S. Karger AG, Basel

E-Mail karger@karger.com

www.karger.com/iaa
However, a diminished suppressive function on autologous lymphocytes was found in SSc-derived Tregs. Significant relative hypermethylation was seen at the gene level for $R O R C 1$ and $R O R C 2$ in SSc, particularly in patients with high inflammatory activity. Conclusions: Besides the high transcriptional activity of T cells, attributed to Treg or Th17 phenotype, in active SSc disease, Tregs may be insufficient to produce high amounts of IL-10 or to control proliferative activity of effector T cells in SSc. Our results suggest a high plasticity of Tregs strongly associated with the Th17 phenotype. Future directions may focus on enhancing Treg functions and stabilization of the Treg phenotype.

(c) 2016 S. Karger AG, Basel

\section{Introduction}

Scleroderma is an inflammatory disease of the skin and internal organs resulting in fibrosis and organ dysfunction. There is much evidence that T cells are strongly involved in the pathogenesis of systemic and localized 
forms of scleroderma. A predominance of T helper (Th) 1- and interleukin-17 (IL-17)-producing Th17 cells was found in early inflammation and a shift towards Th2 cytokine signatures in late lesions [1-5]. However, the interpretation of the role of Th17 in systemic scleroderma (SSc) remains controversial. Increased expression of IL17 mRNA by lymphocytes obtained from the skin and lung of SSc patients and elevated serum IL-17 levels suggest a role of IL-17 in the pathogenesis of SSc $[3,6]$. While some studies reported Th17 responses predominate in active disease courses and diffuse manifestations of scleroderma [7], others noted an absence of IL-17 production but a distinct $\mathrm{T}$-cell subpopulation characterized by synthesis of IL-22, i.e. Th22 cells [8].

An imbalance between forkhead-box-protein-3 (FoxP3)+ CD4+ regulatory T cells (Tregs) and inflammatory Th17 cells has been suggested. Fewer FoxP3+ Tregs and IL-10+ cells were found in the skin of scleroderma patients than controls as well as reduced serum IL-10 levels [9]. IL-10 is regarded as an important suppressive cytokine [10] produced by type I Tregs [11]. Others reported normal [12] or increased [13-15] frequencies of circulating FoxP3+ T cells. Frequencies of Th17 cells and FoxP3+ cells were increased in skin biopsies of early SSc manifestation with the number of Th17 cells closely related to disease activity [16]. The recent literature suggests that Th17 and Treg activity is a hallmark of SSc, as Th17-type cytokines can induce both inflammation and fibrosis $[17,18]$. Tissue-selective trafficking of these inflammatory Th cells is mediated by chemokine receptor expression, such as CCR6 in Th17 cells [19].

The Th17-associated transcription factor RORC (RARrelated-orphan-receptor-C) and the Treg-associated transcription factor FOXP3 are both upregulated in naive $\mathrm{T}$ cells and compete for dominance early in T-cell differentiation. While a cytokine milieu dominated by IL- $1 \beta$, IL- 6 , and IL-23 promotes Th17 differentiation, transforminggrowth-factor (TGF)- $\beta$ favors development of Tregs [20]. $\mathrm{ROR} \gamma$ and ROR $\gamma \tau$ are gene products of RORC1 and $R O R C 2$ genes, respectively, with $\mathrm{ROR} \gamma \tau$ being strongly involved in polarization of Th cells towards Th17. Epigenetic regulation of T-cell-specific transcription factors by methylation of regulatory $\mathrm{CpG}$ sites has been suggested to influence the pathogenesis of SSc [21-25].

This study aims (1) to investigate the phenotypical and functional characteristics of Th17 and Tregs in SSc patients depending on disease manifestation and activity, and (2) to correlate these findings with the levels and methylation status of Th17- and Treg-specific transcription factors.

\section{Patients and Methods}

\section{Study Population}

Blood samples were obtained from patients classified with limited cutaneous (lcSSc) and diffuse cutaneous SSc $(\mathrm{dcSSc})[26,27]$ and healthy controls (HC) at the Departments of Internal Medicine II and Dermatology, Venereology, and Allergology (University Hospital Würzburg) upon written informed consent. The study was performed according to the principles of the Declaration of Helsinki 2010 and approved by the local ethics committee (protocol No. 242/11).

\section{Lymphocyte Separation}

Peripheral blood mononuclear cells (PBMCs) were obtained by density gradient centrifugation (FicoLite-H; Linaris, Wertheim, Germany) from freshly drawn venous blood. After washing steps, cells were resuspended in RPMI 1640 medium (Sigma, St. Louis, MO, USA) supplemented with $10 \%$ fetal calf serum (FCS) and $1 \%$ penicillin/streptomycin.

\section{Cell Surface and Intracellular Staining of T Cells}

PBMCs were resuspended in FACS buffer containing phosphate-buffered saline ( $\mathrm{pH} 7.2), 0.5 \%$ bovine serum albumin, and $0.01 \% \mathrm{NaN}_{3}$ and stained with fluorochrome-labeled monoclonal antibodies against CD3, CD4, CD8, CD45RA, CD45RO, CD28, CD161 (all purchased from BioLegend, London, UK), chemokine receptor (CCR) 7, CCR6, CD25 (all purchased from BD, Franklin Lakes, NJ, USA), and CD127 (eBioscience, San Diego, CA, USA) for $30 \mathrm{~min}$ at $4^{\circ} \mathrm{C}$. For intracellular staining of FoxP3 or ROR $\gamma \tau$ (both purchased from $\mathrm{BD}$ ), cells were fixed using fixation buffer (BioLegend) for $20 \mathrm{~min}$ at room temperature followed by a washing step with permeabilization buffer (BioLegend). Cells were then incubated with monoclonal antibody against FoxP3 or ROR $\gamma \tau$ for 30 min at $4^{\circ} \mathrm{C}$ and resuspended in FACS buffer.

Intracellular cytokine production was determined following stimulation with phorbol 12 -myristate 13 -acetate $(0.03 \mu \mathrm{g} / \mathrm{mL})$, ionomycin $(1 \mu \mathrm{g} / \mathrm{mL})$, and brefeldin $\mathrm{A}(10 \mu \mathrm{g} / \mathrm{mL})$ for $4 \mathrm{~h}$ at $37^{\circ} \mathrm{C}$. Cells were fixed for $20 \mathrm{~min}$ at room temperature using fixation buffer (BD) followed by a washing step with permeabilization buffer and stained using monoclonal antibodies against IL-4, IL-10, IL-17, and IFN $\gamma$ (all purchased from BioLegend). Surface and intracellular expression was assessed by flow cytometry (FACSCanto II; BD). Data analysis was performed using FACSDiva software V6 (BD).

\section{Serum Cytokine Levels}

Serum cytokine levels were measured by flow cytometry with the FlowCytomix multiple analyte detection system for human Th1/Th2/Th9/Th17/Th22 (eBioscience).

\section{Suppression Assay}

As significant differences regarding Tregs were found between dcSSc and HC, CD4+CD25+CD127- cells (Tregs) were isolated from PBMCs obtained from $6 \mathrm{dcSSc}$ and $4 \mathrm{HC}$ using the MACS regulatory T-cell isolation kit II (Miltenyi Biotec, Bergisch Gladbach, Germany) according to the manufacturer's instructions. To track the proliferative capacity of autologous PBMCs in coculture with Tregs, PBMCs were labeled with carboxyfluorescein succinimidyl ester (CFSE) $(10 \mu \mathrm{M})$; 30,000 Tregs and 30,000 CFSE-labeled PBMCs were cocultured at a ratio of 1:1 in RPMI 1640 medium supplemented with $1 \%$ penicillin/streptomycin and 7\% FCS 
Table 1. Demographics of the study groups

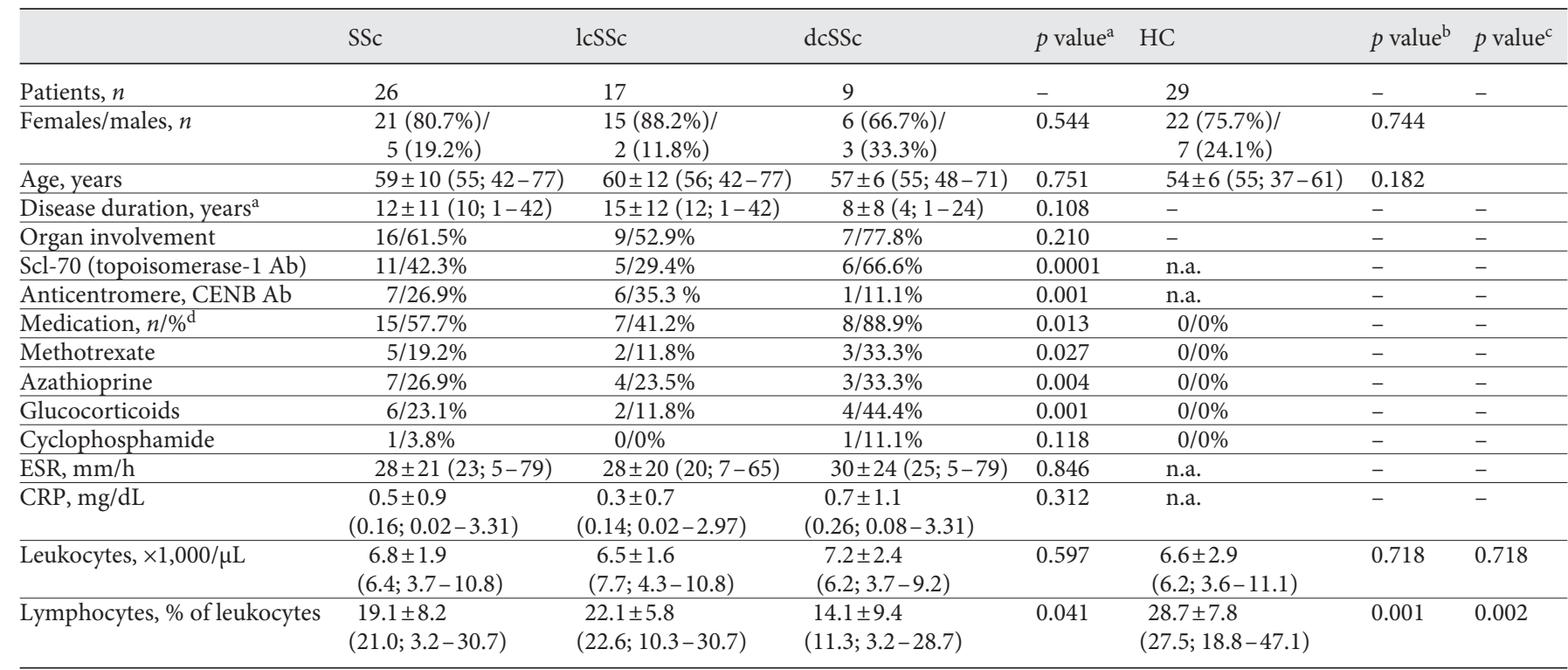

Values are given as means \pm SD (medians; ranges). Ab, antibodies; n.a., not analyzed. ${ }^{a}$ lcSSc vs. dcSSc. ${ }^{b}$ SSc vs. HC. ${ }^{c}$ dcSSc vs. HC. ${ }^{\mathrm{d}}$ Drugs: methotrexate (dosage $10-15 \mathrm{mg} / \mathrm{m}^{2}$ per week; maximum of $25 \mathrm{mg} /$ week); azathioprine (dosage $1-3 \mathrm{mg} / \mathrm{kg} /$ day); glucocorticoids (prednisone equivalent dosage $<0.5 \mathrm{mg} / \mathrm{kg} /$ day; maximum of $60 \mathrm{mg} /$ day); cyclophosphamide (dosage: bolus of $800 \mathrm{mg} / \mathrm{m}^{2}$ ).

The following definitions of organ involvement were used [22]: renal: histologically proven renal thrombotic microangiopathy, histologically proven glomerulonephritis, documented scleroderma renal crisis; heart: pericardial effusion without alternative evident cause, biopsy-proven myocardial involvement, signs and symptoms of cardiomyopathy or conduction abnormalities with typical findings in MRI without alternative evident cause; pulmonary arterial hypertension: defined by right heart catheterization according to European Society of Cardiology/European Respiratory Society guidelines; lung: compatible intestinal lung disease in computed tomography; gastrointestinal system: documentation of required hyperalimentation, and pseudo-obstruction, esophageal dysmotility was not included as GI system involvement as it is known to be very common among SSc patients. Meeting at least one feature of these definitions was required to allow categorization as "organ involvement."

Exclusion criteria were other autoimmune disorders, immunodeficiency, genetic syndromes, clinically symptomatic infections during the 6 weeks prior to inclusion and the administration of blood or plasma products (erythrocyte or thrombocyte concentrates, or intravenous immunoglobulins) in the past 3 months. Female and male patients did not significantly differ with respect to disease duration, age, medications, inflammatory parameters (ESR or CRP), leukocyte counts, relative lymphocytes or presence of auto-antibodies (Scl-70 or anticentromere). No correlation was noted between disease duration and patient age.

and stimulated with $0.5 \mu \mathrm{g} / \mathrm{mL}$ anti-CD3/anti-CD28 for 5 days. Different ratios of Tregs:PBMCs were tested in preliminary experiments to prove specificity. A ratio of 1:1 was confirmed to have the highest effect. After harvesting cells, proliferating and resting PBMCs were stained with fluorochrome-labeled anti-CD4 and analyzed by flow cytometry. The stimulation index was defined as proliferation of CD4+ T cells in coculture with Tregs divided by the proliferation of PBMCs or CD4+ T cells without Tregs. From preliminary experiments, apoptosis measured by propidium iodide/annexin $\mathrm{V}$ was similar between samples from dcSSc patients and HC.

\section{Bisulfite Pyrosequencing}

Assays quantifying the methylation levels of CpGs in the target regions were designed with the PyroMark Assay Design software (Qiagen, Hilden, Germany). Primers and sequences analyzed are listed in online supplementary Tables 1 and 2 (for all online suppl. material, see www.karger.com/doi/10.1159/000450949). From flow-cytometric results, significant alterations were expected for $\mathrm{dcSSc}$, thus, pyrosequencing was performed only with samples from dcSSc patients. Bisulfite conversion of DNA derived from PBMCs of 9 dcSSc and $5 \mathrm{HC}$ was performed using the EpiTect96 Bisulfite Kit (Qiagen) according to manufacturer's protocol. PCR amplifications were performed on a Tetrad 2 cycler (Bio-Rad, Munich, Germany), and products were separated on $1.5 \%$ agarose gel. Bisulfite pyrosequencing was performed on a PyroMarkTMQ96 MD Pyrosequencing System with the PyroMark Gold Q96 CDT Reagent Kit (Qiagen). The sequences analyzed by bisulfite pyrosequencing are listed in online supplementary Tables 1 and 2. Data analysis was done with the Pyro Q-CpG software (Qiagen).

\section{PCR}

Total RNA was extracted from PBMCs derived from 5 patients with dcSSc and $5 \mathrm{HC}$ using the RNeasy mini kit (Qiagen). Complementary DNA (cDNA) was generated from $1 \mu \mathrm{g}$ RNA using oligo $(\mathrm{dT})_{18}$ primers (Thermo Scientific, Waltham, MA, USA) for reverse transcription with Maxima reverse transcriptase (Thermo Scientific). Real-time PCR was performed using the applied Biosystems ${ }^{\circledR}$ Real-Time PCR7500 (Applied Biosystems, Darmstadt, Germany) utilizing iTaq universal SYBR Green according to the manufacturer's instructions (Bio-Rad, Ismaning, Germany) (for primer sequences see online suppl. Table 3). Amplification was conducted for 40 cycles. Relative expression of FOXP3, RORC, STAT3 (signal transducer and activator of transcription) 3, STAT5, CCR6, $I L-10$, and $I L-17$ were determined by normalizing expression of each gene to $\beta_{2}$-microglobulin. 
Fig. 1. Representative flow cytometry staining for CCR6+CD4+ T cells and Tregs. The gating strategy and representative examples of flow cytometry staining for CD4, CCR6, and IL-17 are shown for $1 \mathrm{dcSSc}$ patient and $1 \mathrm{HC}(\mathbf{A})$. Representative examples of flow-cytometric staining for CD4, CD25, CD127, and FoxP3+ are shown for $1 \mathrm{dcSSc}$ patient and $1 \mathrm{HC}(\mathbf{B})$. Numbers in quadrants represent percentages of positive events in gated regions.
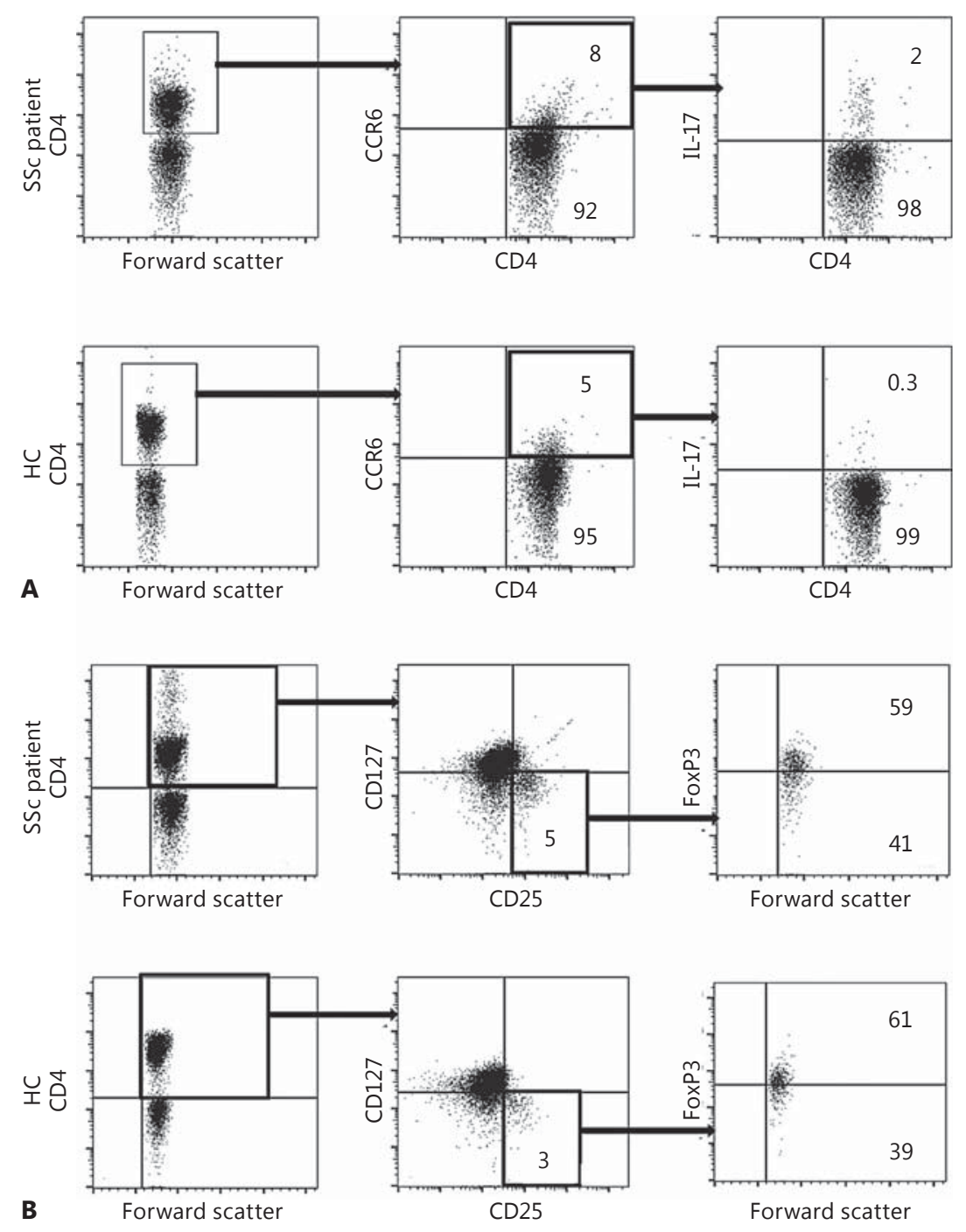

\section{Statistical Analysis}

After testing the distribution of variables with the Shapiro-Wilk test, the Mann-Whitney U test was applied for nonnormally distributed independent variables using SPSS (version 22; SPSS, Chicago, IL, USA). The Wilcoxon rank test was used for nonnormally distributed dependent variables. To avoid bias by multiple testing, a value of $p \leq 0.05$ was considered statistically significant using the less conservative Benjamini-Hochberg correction to reduce false-positive results. Correlations were analyzed by the Spearman rank correlation. In search for independent factors influencing Th17 or Treg functions, step-down multiple regression analysis was performed including age, gender, disease duration, presence of autoantibodies (Scl70/anti-centromere antibodies), organ involvement, erythrocyte sedimentation rate (ESR), C-reactive protein (CRP), and different therapies (methotrexate, glucocorticoids, and azathioprine).

\section{Results}

\section{dcSSc Patients Present with Relative Lymphopenia}

Despite similar leukocyte counts, relative lymphopenia was seen in dcSSc when compared to lcSSc and HC (Table 1). In dcSSc, the reduction in lymphocyte proportions correlated with increased $\operatorname{ESR}(R=-0.667 ; p=0.05)$ and CRP $(R=-0.0748 ; p=0.02)$. ESR and CRP were associated with organ involvement (correlation for ESR: $R=0.725, p=0.027$; CRP: $R=0.678 ; p=0.045)$. dcSSc received more intense medical treatments than lcSSc ( Table 1). 


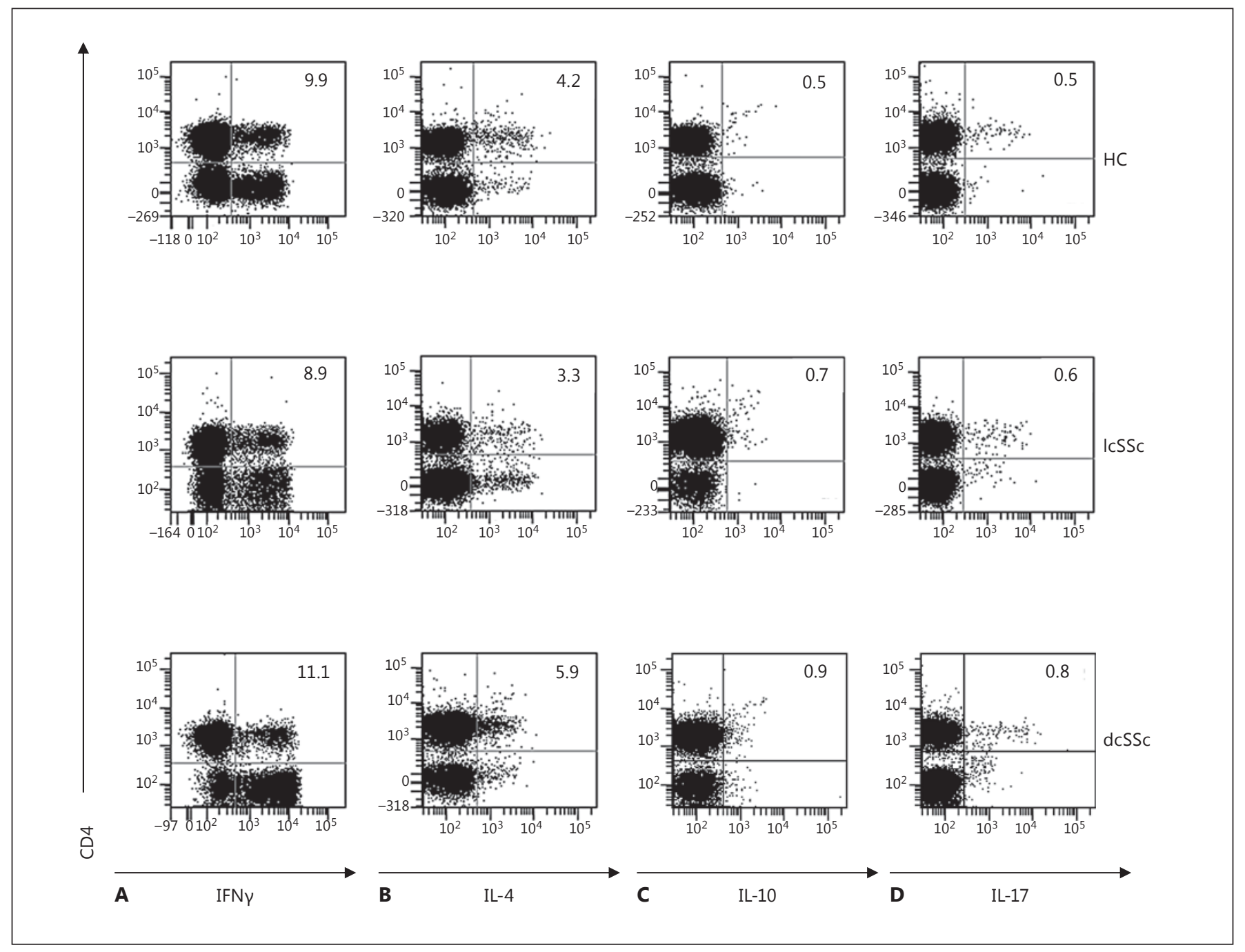

Fig. 2. Representative flow-cytometric staining for intracellular cytokines. Representative examples of flow-cytometric staining for CD4 (y-axis) and cytokines (x-axis) are shown for $1 \mathrm{HC}$ (upper row), $1 \mathrm{lcSSc}$ patient (middle row), and $1 \mathrm{dcSSc}$ patient (lower row). Numbers in the right upper quadrants represent percentages of cytokine-positive CD4+ T cells. Intracellular IFN $\gamma$ was used as a key cytokine for Th1 cells (A), IL-4 for Th2 cells (B), IL10 for Tregs (C), and IL-17 for Th17 cells (D).
Increased Circulating Th17 and CCR6+ T Cells in dcSSc

CCR6 expression was used as a characteristic marker of IL-17-producing cells [3-8] (Fig. 1A). Significantly higher proportions of IL-17-producing CD4+ T cells (Fig. 2D, 3D) and CCR6+ (Fig. 3A) T cells were found in dcSSc.

In search for an independent factor influencing proportions of $\mathrm{CD} 4+\mathrm{CCR} 6+$ in SSc, multiple regression analysis $\left(R^{2}=0.324 ; p=0.038\right)$ was performed. Organ involvement $(p=0.015)$ was identified as an independent factor leading to a proportional increase in CD4+CCR6+ in all SSc patients. In the subgroup of dcSSc, female sex $(p=0.013)$, organ involvement $(p=0.025)$, and Scl-70 seropositivity ( $p=0.037$ ) were significant factors for elevated proportions of CD4+CCR6+. In a multiple regression model $\left(R^{2}=0.995 ; p=0.015\right)$ performed in dcSSc, higher IL-17 production by CD4+CCR6+ was significantly influenced by lower chronological age $(p=0.004)$, shorter disease duration $(p=0.033)$, organ involvement $(p=0.012)$, and increased inflammation parameters (ESR, $p=0.021$; CRP, $p=0.037$ ). There was a trend towards the influence of female sex $(p=0.084)$.

A trend towards double positivity for CD161 and CCR6 ( $p=0.077)$ (Fig. 3B) and higher ROR $\gamma \tau$ expression was also seen in $\mathrm{CD} 4+\mathrm{dcSSc}(p=0.061)$ (Fig. 3C). In both 

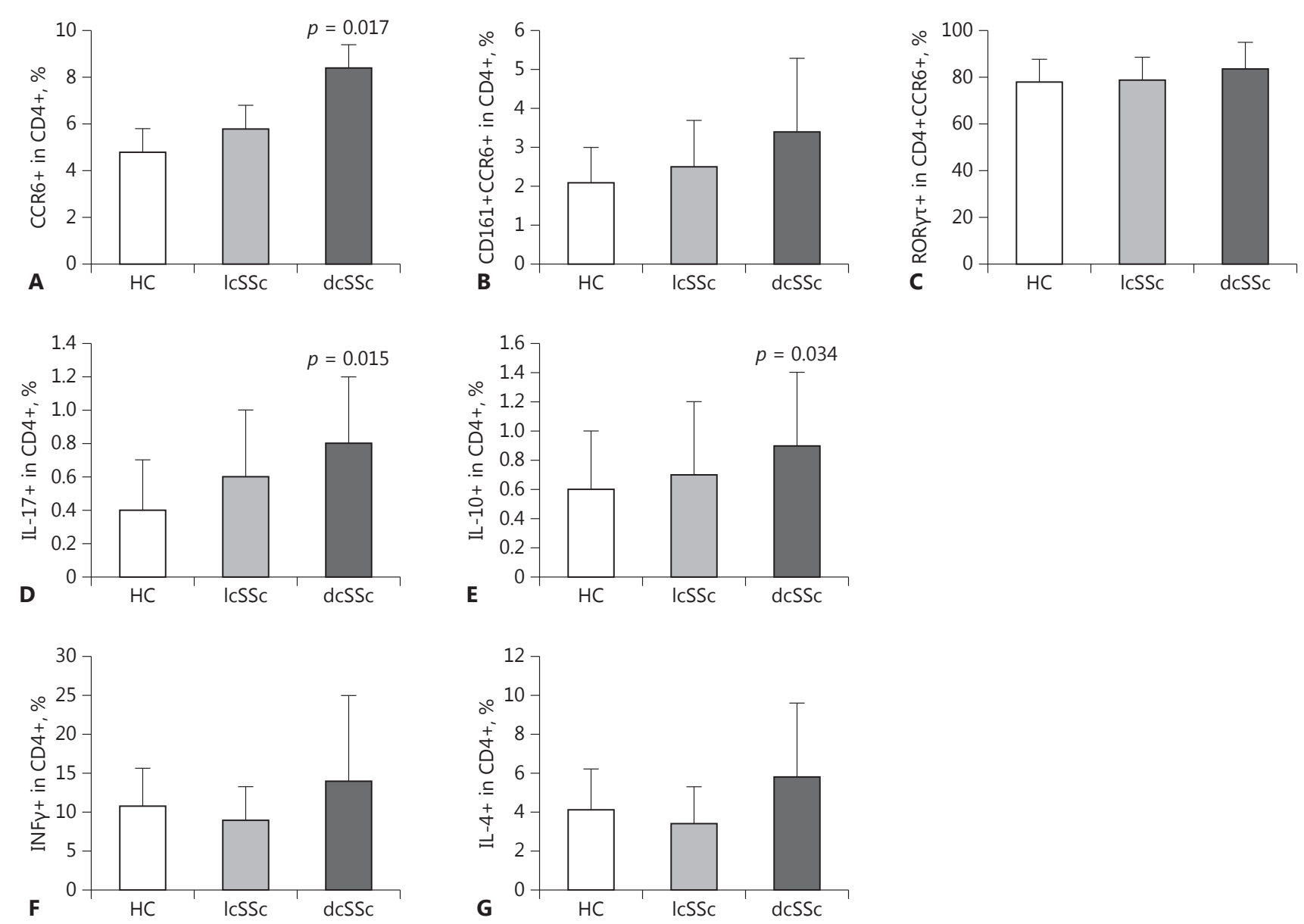

Fig. 3. Proportions of CCR6+ T cells and cytokine-positive CD4+ T cells. Percentages of CCR6+ (A), CD161+CCR6+ (B) in CD4+ T cells, and ROR $\gamma \tau+$ cells in CCR6+CD4+ T cells $(\mathbf{C})$ are shown for $\mathrm{HC}, \mathrm{lcSSc}$, and dcSSc. Intracellular IL-17 was used as a key cyto-

SSc types and HC, CD161 and CCR6 expression strongly correlated with each other $(R=0.835, p=0.0001$, and $R=0.454, p=0.013$, respectively) and was associated with higher age $(R=0.0321, p=0.012)$ and organ involvement $(R=0.0493, p=0.012)$. In dcSSc, ROR $\gamma \tau$ expression strongly correlated with elevated ESR $(R=0.712, p=$ $0.030)$. A trend for a negative correlation with disease duration was recognized for $\mathrm{ROR} \gamma \tau+$ in $\mathrm{CD} 4+\mathrm{CCR} 6+(R=$ $-0.655, p=0.055)$.

Intracellular IFN $\gamma$ and IL-4 productions, key cytokines of Th1 and Th2 cells, respectively, were not significantly different between SSc patients and HC (Fig. 2A, B, 3F, G).

Serum Th17-inducing cytokines (e.g. IL-1 $\beta$ and IL-6) and Th17-producing cytokines (e.g. IL-17A or IL-22) kine for Th17 cells (D), IL-10 for Tregs (E), IFN $\gamma$ for Th1 cells (F), and IL-4 for Th2 cells (G). Bars represent means \pm SD. $p$ value indicates comparison with HC (Mann-Whitney U test).

were not significantly elevated in SSc (Table 2). Also, typical Th1 and Th2 cytokines were not different between serum samples of SSc patients and HC.

\section{Abundance of Circulating FoxP3+ Tregs with} Impaired Suppressive Function in SSc

Significantly higher proportions of CD25++CD127FoxP3+ Tregs were seen in lcSSc and dcSSc compared to $\mathrm{HC}$ (Fig. 1B, 4A). Multiple regression analysis $\left(R^{2}=0.981\right.$, $p=0.05)$ revealed that elevated proportions of Tregs in dcSSc were significantly influenced by increased CRP $(p=0.008)$, female sex $(p=0.031)$, and shorter disease duration $(p=0.040)$. There was a trend towards the influence of elevated ESR $(p=0.080)$ and Scl-70+ $(p=0.077)$. 
Table 2. Serum cytokine concentrations

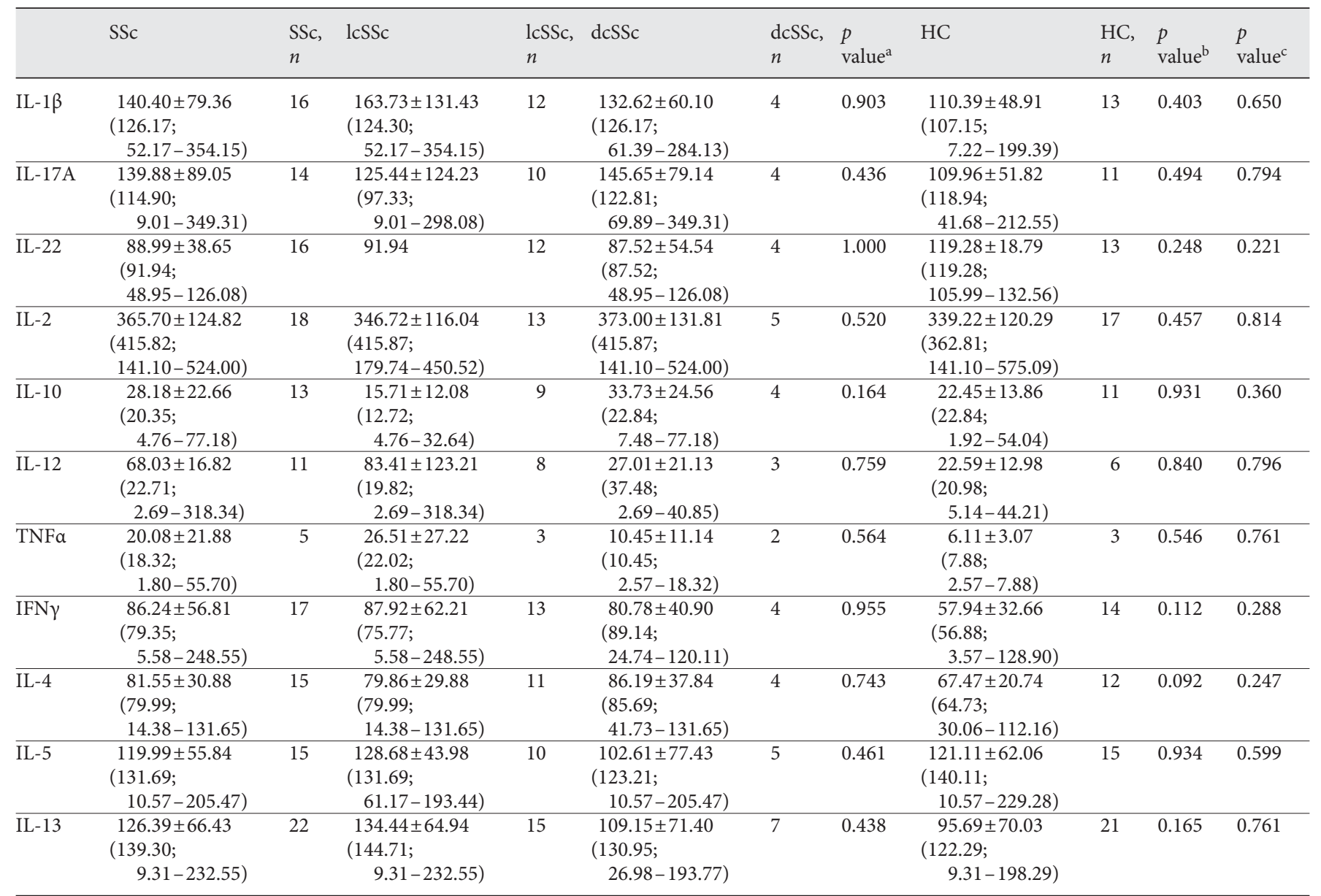

Values are given as means \pm SD (medians; ranges) in $\mathrm{pg} / \mathrm{mL}$. The numbers of patients who had detectable concentrations of the specific cytokines are indicated for each group. IL-22 was positive in only 1 lcSSc patient. IL- 6 and TGF $\beta$ were negative in all donors. IL- $1 \beta$, IL-6, IL-17A, and IL-22 were considered to be Th17 cytokines, IL-2 and IL-10 as cytokines of induced Tregs, IL-12, TNFa, and IFN $\gamma$ Th1 cytokines, and IL-4, IL-5, and IL-13 Th2 cytokines. ${ }^{a}$ lcSSc vs. dcSSc. ${ }^{b}$ SSc vs. HC. ${ }^{c}$ dcSSc vs. HC.

Table 3. Percentages of IL-10+CD4+ T-cell subpopulations

\begin{tabular}{|c|c|c|c|c|c|c|c|}
\hline Group & $\begin{array}{l}\text { SSc } \\
(n=26)\end{array}$ & $\begin{array}{l}\text { lcSSc } \\
(n=17)\end{array}$ & $\begin{array}{l}\mathrm{dcSSc} \\
(n=9)\end{array}$ & $\begin{array}{l}p \\
\text { value }^{\mathrm{a}}\end{array}$ & $\begin{array}{l}\mathrm{HC} \\
(n=29)\end{array}$ & $\begin{array}{l}p \\
\text { value }^{\mathrm{b}}\end{array}$ & $\begin{array}{l}p \\
\text { value }^{\mathrm{c}}\end{array}$ \\
\hline $\begin{array}{l}\mathrm{CD} 45 \mathrm{RA}+\mathrm{CD} 28+\mathrm{CCR} 7+ \\
\text { (naive) }\end{array}$ & $\begin{array}{l}3.09 \pm 8.59 \\
(0.95 ; 0.1-44.7)\end{array}$ & $\begin{array}{l}1.97 \pm 1.94 \\
(1.09 ; 0.1-6.1)\end{array}$ & $\begin{array}{l}3.68 \pm 10.60 \\
(0.89 ; 0.6-44.7)\end{array}$ & 0.346 & $\begin{array}{l}1.01 \pm 1.22 \\
(0.64 ; 0.3-5.4)\end{array}$ & 0.003 & 0.027 \\
\hline $\begin{array}{l}\text { CD45RA-CD28+CCR7+ } \\
\text { (early memory) }\end{array}$ & $\begin{array}{l}3.07 \pm 10.70 \\
(0.66 ; 0-55.2)\end{array}$ & $\begin{array}{c}0.81 \pm 0.77 \\
(0.44 ; 0-1.9)\end{array}$ & $\begin{array}{l}4.27 \pm 13.20 \\
(0.67 ; 0.1-55.2)\end{array}$ & 0.500 & $\begin{array}{c}0.64 \pm 0.59 \\
(0.37 ; 0-2.5)\end{array}$ & 0.194 & 0.668 \\
\hline $\begin{array}{l}\text { CD45RA-CD28-CCR7+ } \\
\text { (late memory) }\end{array}$ & $\begin{array}{l}6.44 \pm 13.77 \\
(2.07 ; 0-63.6)\end{array}$ & $\begin{array}{c}1.07 \pm 1.30 \\
(0.00 ; 0-3.0)\end{array}$ & $\begin{array}{l}9.28 \pm 16.45 \\
(3.45 ; 0-63.6)\end{array}$ & 0.089 & $\begin{array}{c}1.34 \pm 2.35 \\
(0.00 ; 0-6.5)\end{array}$ & 0.048 & 0.723 \\
\hline $\begin{array}{l}\text { CD45RA+CD28-CCR7- } \\
\text { (TEMRA) }\end{array}$ & $\begin{array}{l}4.15 \pm 10.01 \\
(1.14 ; 0-50.0)\end{array}$ & $\begin{array}{l}3.64 \pm 4.10 \\
(1.72 ; 0-11.4)\end{array}$ & $\begin{array}{l}4.42 \pm 12.16 \\
(0.00 ; 0-50.0)\end{array}$ & 0.134 & $\begin{array}{l}1.91 \pm 3.61 \\
(0.23 ; 0-16.7)\end{array}$ & 0.245 & 0.027 \\
\hline
\end{tabular}

Values are given as means \pm SD (medians; ranges) in percentages of IL-10+CD4+ T-cell subpopulations. $n$, numbers of patients. ${ }^{a}$ lcSSc vs. dcSSc. ${ }^{b}$ SSc vs. HC. ${ }^{c}$ dcSSc vs. HC. 


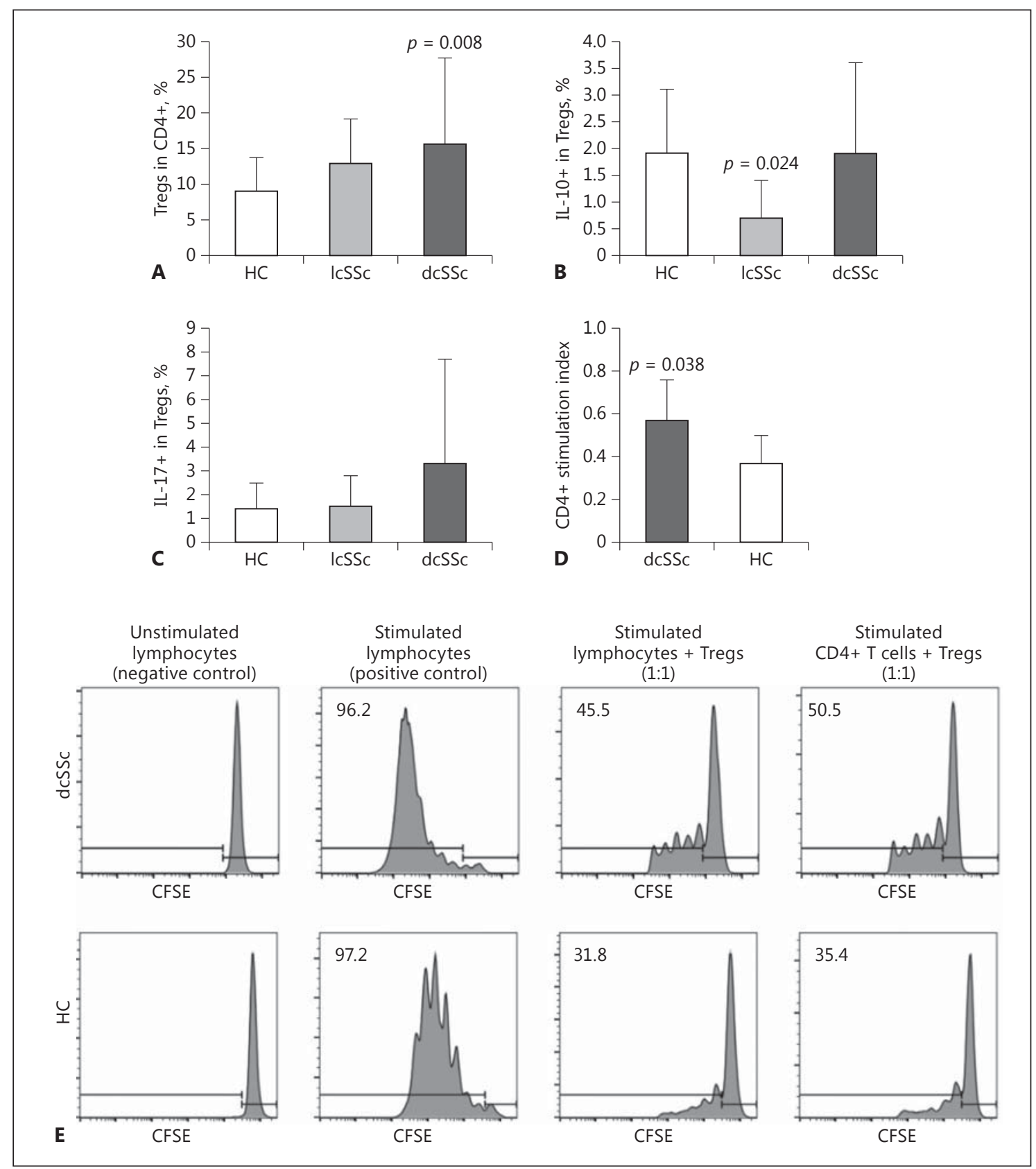

Fig. 4. Proportions of Tregs and suppressive function. Percentages of Tregs (CD25++FoxP3+CD127-) (A) and IL-10+ (B), or IL-17+ cells $(\mathbf{C})$ in Tregs are shown in $\mathrm{HC}, \mathrm{lcSSc}$, and dcSSc. Bars represent means + SD. $p$ values indicate comparisons with HC (Mann-Whitney $\mathrm{U}$ test). D Results from suppression assays are shown. The stimulation index was defined as proliferation of CD4+ T cells in coculture with Tregs divided by the proliferation of CD4+ T cells without Tregs. E Representative examples of a suppression assay from 1 patient with dcSSc and $1 \mathrm{HC}$ are shown. CFSE staining of lymphocytes and CD4+ T cells is shown on the $\mathrm{x}$-axis. The cutoff for proliferating cells was adjusted to negative controls. Numbers in histograms represent the percentages of proliferated cells.
IL-10 was poorly produced by Tregs of lcSSc (Fig. 4B) but to a significant extend in CD4+ T cells (Fig. 2C, 3E) and CD4+ T-cell subpopulations, particularly in naive, late memory-effector and terminally differentiated effec- tor-memory CD4+ T cells reexpressing CD45RA (TEMRA) of dcSSc (Table 3). In dcSSc, serum IL-10 tended to be higher than in lcSSc (Table 2). Scl-70+ patients were more likely to have lower IL-10+CD4+ T-cell propor- 


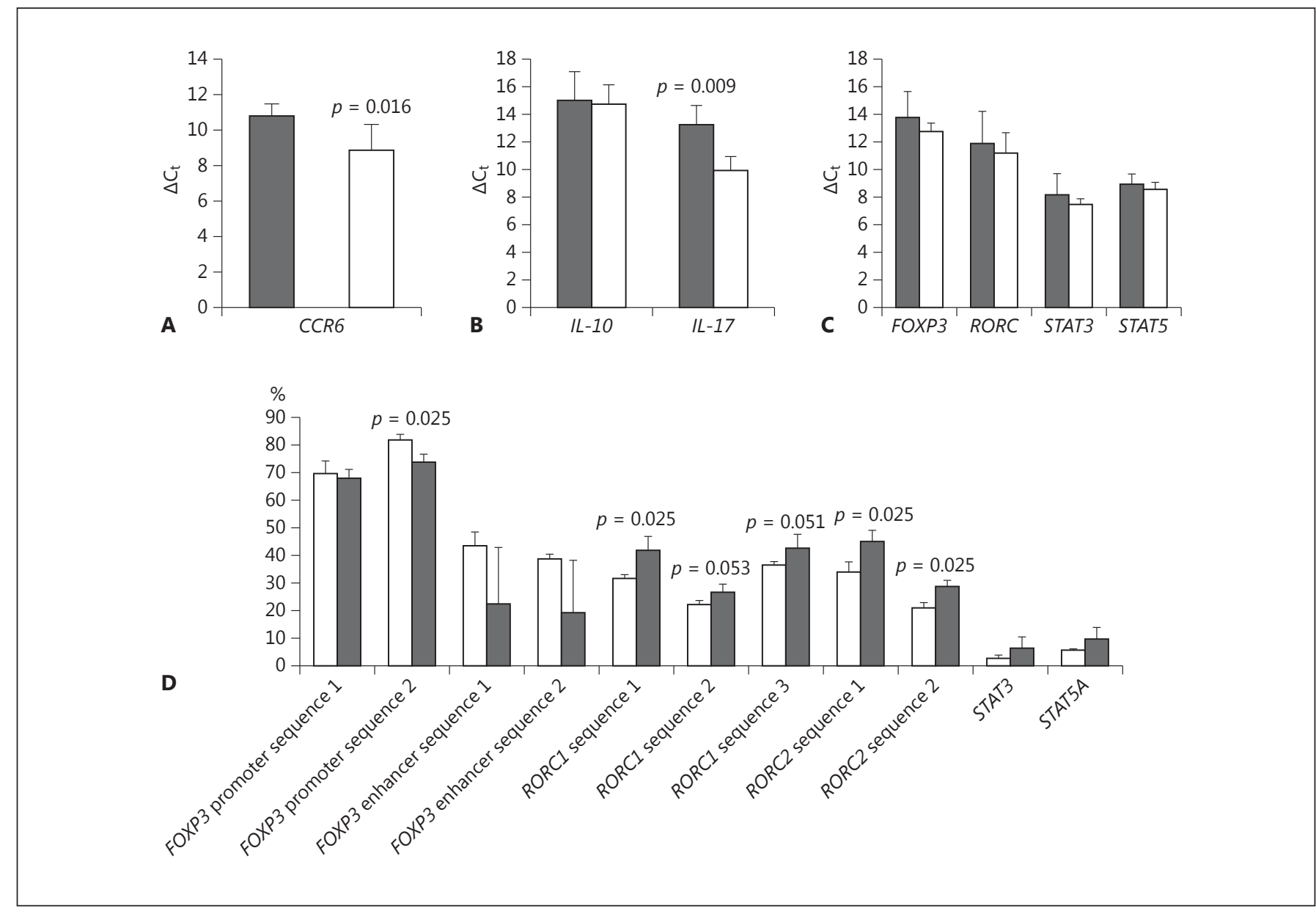

Fig. 5. Expression profile and methylation status. $\Delta \mathrm{C}_{\mathrm{t}}$ values $(\mathrm{y}-$ axis) are given for CCR6 (A), $I L-10$ and $I L-17$ (B), and FOXP3, RORC, STAT3, and STAT5 (C) in patients with dcSSc (gray bars) and $\mathrm{HC}$ (white bars). $p$ values indicate comparisons between dcSSc and HC (Mann-Whitney U test). D Percentages of transcription factor methylation stratified for low ESR ( $<10 \mathrm{~mm} / \mathrm{h}$ ) (white bars) and high ESR ( $\geq 10 \mathrm{~mm} / \mathrm{h}$ ) (gray bars) are shown in dcSSc patients. $p$ values indicate comparisons between low and high ESR (MannWhitney U test). tions than Scl-70- patients $(p=0.05)$. Consulting a significant regression model for influencing factors of IL$10+\mathrm{CD} 4+$ in dcSSc $\left(R^{2}=0.956, p=0.030\right)$, shorter disease duration $(p=0.007)$ as well as lack of organ involvement $(p=0.029)$, and lower inflammation parameters (ESR, $p=0.026$; CRP, $p=0.046$ ) had a significant impact on higher proportions of IL-10+CD4+. Serum IL-2, an autocrine stimulating cytokine for Tregs, was not different between SSc and HC (Table 2).

No correlation was seen between Tregs and IL17-producing CCR6+CD4+ in any group. Tregs demonstrated to be IL-17 producers to a low extent, too, but no significant difference could be found between SSc and $\mathrm{HC}$ (Fig. 4C). However, a positive association was found between IL-17+ Tregs and organ involvement
$(R=0.403, p=0.046)$. IL-17+ Tregs positively correlated with CCR6+CD161+CD4+ in dcSSc $(R=0.767$, $p=0.016)$. However, removing IL-17+ Tregs from the FoxP3+ Tregs in flow-cytometric analysis did not change the result that higher proportions of Tregs were found in SSc compared to HC. In all SSc patients, IL-10+ Tregs also correlated with CCR6+ $(R=0.453$, $p=0.023)$ and CCR6+CD161+CD4+ T cells $(R=0.421$, $p=0.036)$.

Despite the peripheral abundance of Tregs found in SSc, the functional activity of Tregs was unclear. Investigating the suppressive function of Tregs, lower suppression of autologous lymphocytes or CD4+ T cells was demonstrated by Tregs derived from dcSSc compared to Tregs derived from HC (Fig. 4D, E). 
Table 4. Methylation status of Treg- and Th17-specific transcription factors

\begin{tabular}{|c|c|c|c|c|c|c|}
\hline & \multicolumn{2}{|l|}{ dcSSc } & \multicolumn{2}{|l|}{$\mathrm{HC}$} & \multicolumn{2}{|c|}{$p$ value } \\
\hline & male $(n=3)$ & female $(n=6)$ & male $(n=4)$ & female $(n=6)$ & male & female \\
\hline FOXP3 sequence 1 & $\begin{array}{l}65.38 \pm 4.47 \\
(66.48 ; 58.07-69.89)\end{array}$ & $\begin{array}{l}68.69 \pm 4.41 \\
(69.89 ; 60.67-73.02)\end{array}$ & $\begin{array}{l}63.59 \pm 6.54 \\
(59.79 ; 57.91-71.15)\end{array}$ & $\begin{array}{l}63.91 \pm 2.74 \\
(62.45 ; 61.78-68.52)\end{array}$ & 0.917 & 0.062 \\
\hline FOXP3 sequence 2 & $\begin{array}{l}72.88 \pm 1.74 \\
(73.44 ; 70.45-74.91)\end{array}$ & $\begin{array}{l}78.32 \pm 3.92 \\
(77.98 ; 72.76-84.00)\end{array}$ & $\begin{array}{l}71.09 \pm 4.02 \\
(70.00 ; 65.68-76.00)\end{array}$ & $\begin{array}{l}76.29 \pm 3.10 \\
(75.75 ; 73.24-81.25)\end{array}$ & 0.465 & 0.317 \\
\hline FOXP3 enhancer sequence 1 & $\begin{array}{l}6.68 \pm 4.24 \\
(3.81 ; 3.36-12.34)\end{array}$ & $\begin{array}{l}43.46 \pm 3.15 \\
(43.31 ; 38.94-48.87)\end{array}$ & $\begin{array}{l}5.40 \pm 2.66 \\
(3.63 ; 3.24-8.72)\end{array}$ & $\begin{array}{l}41.80 \pm 5.05 \\
(43.12 ; 34.91-47.22)\end{array}$ & 0.347 & 0.668 \\
\hline FOXP3 enhancer sequence 2 & $\begin{array}{l}4.98 \pm 3.16 \\
(3.17 ; 2.43-9.96)\end{array}$ & $\begin{array}{l}38.91 \pm 2.78 \\
(39.44 ; 34.19-41.93)\end{array}$ & $\begin{array}{l}4.90 \pm 3.64 \\
(2.71 ; 1.71-9.50)\end{array}$ & $\begin{array}{l}34.82 \pm 10.46 \\
(39.46 ; 15.52-43.98)\end{array}$ & 0.465 & 0.668 \\
\hline STAT5A sequence 1 & \multicolumn{2}{|c|}{$8.01 \pm 3.22(6.77 ; 4.87-14.39)$} & \multicolumn{2}{|c|}{$9.02 \pm 2.20(8.64 ; 6.21-11.51)$} & \multicolumn{2}{|l|}{0.140} \\
\hline RORC1 sequence 1 & \multicolumn{2}{|c|}{$37.04 \pm 6.64(35.41 ; 25.16-47.60)$} & \multicolumn{2}{|c|}{$28.24 \pm 4.59(28.52 ; 19.98-33.22)$} & \multicolumn{2}{|l|}{0.003} \\
\hline$R O R C 1$ sequence 2 & \multicolumn{2}{|c|}{$24.38 \pm 4.41(24.40 ; 15.55-29.83)$} & \multicolumn{2}{|c|}{$18.14 \pm 3.14(17.52 ; 12.55-21.95)$} & \multicolumn{2}{|l|}{0.004} \\
\hline RORC1 sequence 3 & \multicolumn{2}{|c|}{$39.04 \pm 4.85(37.54 ; 33.75-49.68)$} & \multicolumn{2}{|c|}{$31.87 \pm 3.45(33.27 ; 24.58-35.84)$} & \multicolumn{2}{|l|}{0.001} \\
\hline RORC2 sequence 1 & \multicolumn{2}{|c|}{$40.12 \pm 6.73(39.55 ; 29.22-49.59)$} & \multicolumn{2}{|c|}{$32.17 \pm 4.50(31.98 ; 26.05-40.38)$} & \multicolumn{2}{|l|}{0.010} \\
\hline RORC2 sequence 2 & \multicolumn{2}{|c|}{$25.71 \pm 4.33(27.10 ; 19.05-31.79)$} & \multicolumn{2}{|c|}{$20.67 \pm 3.69(20.78 ; 17.53-20.78)$} & \multicolumn{2}{|l|}{0.016} \\
\hline STAT3 sequence 1 & \multicolumn{2}{|c|}{$4.64 \pm 3.10(3.45 ; 2.17-12.49)$} & \multicolumn{2}{|c|}{$4.42 \pm 3.05(2.84 ; 2.17-11.21)$} & \multicolumn{2}{|l|}{0.806} \\
\hline
\end{tabular}

Values are given as means \pm SD (medians; ranges) in mean percentages of methylation.

\section{Alterations at the Transcriptional Level of Th17 and Tregs of dcSSc}

CCR6 (Fig. 5A) and $I L-17$ expression (Fig. 5B) was elevated in dcSSc. IL-10 expression was similar to HC (Fig. 5B). The Th17-specific transcription factor RORC and the downstream regulator of Th17 differentiation STAT3, as well as the Treg-specific transcription factor FOXP3 and the downstream regulator for Treg differentiation STAT5, were not found to be differently expressed in peripheral lymphocytes of dcSSc compared to $\mathrm{HC}$ (Fig. 5C). However, FOXP3+ expression correlated positively with $I L-17$ expression $(R=0.900, p=0.037), R O R C$ expression correlated negatively with $I L-10$ expression $(R=-0.900, p=0.037)$. CCR6 expression was positively associated with STAT3 expression $(R=0.900, p=0.037)$.

\section{Hypermethylation of RORC in dcSSc Patients}

The methylation status of Th17 and Treg-specific transcription factors was analyzed to determine transcriptional activity. Significant hypermethylation was found for all RORC1 and RORC2 CpG positions in dcSSc (Table 4; online suppl. Table 4) which correlated with each other $(R=0.846, p=0.001)$. Mean methylation at $R O R C 1$ was negatively associated with PCR products of $R O R C(R=-0.900, p=0.037)$.

As epigenetic regulation may be influenced by inflammatory parameters, methylation levels were statistically correlated to proportions of different CD4+ subpopulations, to inflammatory disease activity stratified by elevated ESR $\geq 10 \mathrm{~mm} / \mathrm{h}$ (Fig. 5D), and to prevalence of spe- cific antibodies. Hypermethylation of RORC1 and RORC2 correlated with CD161+CCR6+CD4+ and ESR, with strongest effects in sequence 2 of RORC2 (CD161+ CCR6+CD4+: $R=0.806, p=0.005$; ESR: $R=0.970, p=$ $0.0001)$. Higher methylation levels at $R O R C 1$ and $R O R C 2$ were also seen in Scl-70+ compared to Scl-70- patients $(p=0.020)$.

Multiple regression analysis $\left(R^{2}=0.989, p=0.026\right)$ revealed that higher inflammatory parameters (ESR: $p=$ 0.016 ; CRP $=0.028)$, older age $(p=0.064)$, and Scl-70 seropositivity ( $p=0.084$ ) had the strongest influence on $R O R C 2$ sequence 2 methylation levels.

Due to the X-chromosomal location of FOXP3, highly significant methylation of FOXP3 promoter and enhancer regions were seen in female compared to male dcSSc and HC (female vs. male: $p=0.008$ ). Relative hypermethylation at the FOXP3 promoter locus was seen only in female dcSSc but not female HC (Table 4; online suppl. Table 4). Lower methylation at sequence 2 within the $F O X P 3$ promoter was associated with higher inflammatory parameters (ESR: $R=-0.862, p=0.006$; CRP: $R=$ $-0.653, p=0.057)$, which also correlated with sequence 1 and 2 of the enhancer regions $(R=-0.728, p=0.026$, and $R=-0.594, p=0.092$, respectively). In dcSSc, methylation levels between sequence 1 and 2 of FOXP3 promoter regions $(R=0.0585, p=0.046)$ and enhancer regions $(R=$ $0.0746, p=0.005)$ correlated with each other. In dcSSc, higher mean methylation levels at the sequence 2 FOXP3 promoter region correlated with lower methylation levels at sequence 1 of $R O R C 1$ regions $(R=-0.643, p=0.024)$. 
Mean methylation at FOXP3 enhancer region sequence 2 was negatively associated with PCR products of the FOXP3 $(R=-0.900, p=0.037)$.

Although there was no significant difference in methylation levels at STAT3 between dcSSc and HC, mean methylation at the STAT3 locus was associated with increased disease duration $(R=0.675, p=0.032)$. In dcSSc, $S T A T 3$ methylation levels were also positively correlated with STAT5A $(R=0.671, p=0.017)$ and $R O R C 1$ sequence 1 methylation $(R=0.706, p=0.010)$, and negatively with FOXP3 promoter sequence 1 methylation $(R=-0.900$, $p=0.037)$. Correlation to the other RORC1 and RORC2 sequences was less significant $(R=0.529, p=0.077)$. Hypomethylation of STAT5A at position 1 was seen in $\mathrm{dcSSC}$ compared to HC (online suppl. Table 4).

\section{Discussion}

Our findings demonstrated a concomitant abundance of peripheral IL-17-producing CCR6+ Th cells and FoxP3+ Tregs in patients with dcSSc. Associations of Th17- and Treg-associated characteristics were seen with early, active, and severe disease. However, a diminished suppressive function on autologous lymphocytes was found in SSc-derived Tregs. At the transcriptional level, Th17-associated factors were elevated in dcSSc. Significant relative hypermethylation at the gene level for $R O R C 1$ and $R O R C 2$ in dcSSc was strongly associated with elevated ESR.

Our results confirmed earlier findings that Th17 responses predominate in active disease courses with elevated inflammatory blood parameters and diffuse manifestations of SSc $[3-5,7,28]$. Moreover, our findings demonstrated higher Th17-associated markers with lower chronological age or shorter disease duration, indicating an important role of Th17 in the early stages of the disease. Percentages of CD161+CD4+ were increased in SSc [29-32] and correlated with percentages of IL-17Aproducing cells [33] with high expression of CCR6 [34]. Our study demonstrated a trend to higher proportions of CD161 and CCR6 double-positive CD4+ in dcSSc. Scl70-seropositivity was associated with CCR6+CD4+, which was also shown by others [35].

Some inconsistencies exist regarding serum IL-17 levels in SSc [3-5, 36]. In contrast to others [3-5], elevated serum levels of IL-17 or other Th17-associated inflammatory cytokines were not found in our study. Several studies have reported a reduced IL-10 production from PBMCs $[37,38]$, others have found augmented IL-10 concentrations $[39,40]$. However, our data reflect the in- tracellular production of IL-17 or IL-10 in CD4+ Th cell subpopulations and are therefore more likely to explain intrinsic dysfunctions of Th cells than serum cytokine concentrations may do.

Concomitantly with Th17, Tregs were increased in the peripheral blood of dcSSc correlating with disease activity in agreement with others [8]. Increased frequencies of Th17 and FoxP3 + cells were also reported in skin biopsies of early SSc manifestations with the number of Th17 cells closely related to disease activity [16] and severity [41].

Regarding the functional abilities of Tregs, Foxp3+ CD25+ Tregs were found to act suppressive on proliferating cells, as shown by others $[42,43]$. Similar to our results, a diminished suppressive function of Tregs [28] was seen by an overall increased number of Tregs in SSc [13]. Alterations in the Th17 compartment correlated with Treg alterations in each patient [28]. In our study, no correlation between IL-17-producing CCR6+CD4+ and Tregs could be found. Several groups have reported the conversion of Tregs to Th17 cells in both the mouse and humans [44-46], and that Th17 cells derived from Tregs share common features with Th17 cells generated from naive precursors including expression of CCR6 [32, 47]. Thus, a concurrent abundance of Tregs and Th17 in SSc was attributed to the possibility of Tregs to change into Th17 cells. Indeed, increased IL-17-producing cells with high expression of CD25 were observed in SSc [5]. Although a small proportion of Tregs appeared to be IL-17 producers in our study, no differences could be shown for HC and SSc. However, a positive correlation was found between proportions of IL-17+ Tregs and organ involvement, as well as a positive correlation with CCR6+ T cells.

A high plasticity was attributed to the Treg phenotype. Isolation of pure Tregs is a challenge as there are high percentages of CD127 low cells that did not express FoxP3 and, conversely, there was a high percentage of CD127+ cells that expressed FoxP3 [48]. Staining for FoxP3 and CD127 may not always represent the same Treg population and may result in a highly varying number of Tregs in SSc [48]. In our study, removing IL-17+ Tregs from the FoxP3+ Treg pool by retrospective flow-cytometric analysis did not change the finding of increased FoxP3+ Tregs in SSc patients. Studies on the plasticity of CD4+FoxP3+ $T$ cells found that upon stimulation by inflammatory cytokines CD4+FoxP3+ cells may also downregulate FoxP3 expression and produce inflammatory cytokines such as IL-17 and IFN $\gamma[49,50]$. Increased Tregs in SSc [13] were explained by a possible influence of glucocorticoids which may increase CD4+CD25+ cells [51, 52]. In our study, no significant influence of relatively low-dose systemic glu- 
cocorticoids or of any medications on Tregs or Th17 cells was demonstrated.

At the transcriptional level, $I L-17$ and CCR6 were elevated in peripheral lymphocytes of SSc. The discrepancy between nonsignificantly elevated IL-17 serum levels and the ability of T cells to produce high levels of IL-17 may be explained by a predominant local cytokine production in scleroderma lesions, as seen by others $[3,53]$. IL-17 levels were negatively associated with disease duration [53], with elevated IL-17 levels in early SSc disease $[3,53]$. Again, concomitant with $R O R C$ expression, a significant upregulation of FOXP3 was seen in SSc in our study.

Downregulation of FOXP3 gene expression and hypermethylation of the FOXP3 promoter regions were described in SSc patients [25]. In our findings, elevated ESR was associated with hypomethylation at FOXP3 promoter and enhancer $\mathrm{CpG}$ regions and hypermethylation at $R O R C 1$ and RORC2 CpGs. These findings are compatible with the idea of a concurrent abundance of FoxP3+ and Th17 cells. Our findings are in contrast to previously published results showing downregulation of FOXP3 gene expression and hypermethylation of the FOXP3 promoter regions in SSc patients [25]. However, our findings indicate a clear immunological pattern of activated $\mathrm{T}$ cells displaying a regulatory $\mathrm{T}$-cell phenotype going ahead with IL-17-producing CCR6+ T cells in active and early SSc disease. Hypomethylation at the FOXP3 promotor allows stable FOXP3 expression [54]. In functional assays of SSc-derived Tregs, suppressive function on CD25- T cells was low in our study. Thus, besides the high transcriptional activity of $\mathrm{T}$ cells, which is attributed to the Treg or Th17 phenotype, Tregs may be insufficient to produce high amounts of IL-10 or to control proliferative activity of effector T cells in SSc.

In our study, hypermethylation of $R O R C$ regions presented concomitant with higher inflammatory activity in $\mathrm{dcSS} c$ patients. Besides the hypermethylation of $R O R C$ and correlation with reduced PCR products of RORC, Th17 subsets identified by CCR6 cell surface expression and IL17 production were not impaired. The likely explanation for this is that $R O R C$, albeit being a lineage-specific transcription factor for Th17 cells, may not be the sole factor for Th17 differentiation. Moreover, Th17 polarization is influenced by nuclear receptor ROR $\alpha$, STAT3 gene expression, and various interactions between inhibitory factors, such as TBX21 (characteristic for Th1 lineage), FOXP3 (Tregs), or GATA3 (Th2 lineage) [55, 56]. Data regarding the epigenetic regulation of Th17 cell plasticity in mice revealed that permissive and repressive marks exist at the IFN $\gamma$ and IL-17A promoter regions, and may itself influ- ence IL-17 production. The histone methylation patterns at promoters of lineage-specific transcription factors TBX21 and RORC in Th17 cells and Tregs have been shown to display evenly poised bivalent marks which correlate to undergo transdifferentiation in response to the local cytokine milieu [55]. This may explain the difference in RORC methylation levels between dcSSc patients with high systemic inflammatory activity (ESR $\geq 10 \mathrm{~mm} / \mathrm{h}$ ) and patients with ESR $<10 \mathrm{~mm} / \mathrm{h}$. A second explanation for the trend towards higher ROR $\gamma \tau$ expression in CD4+CCR6+ T cells and intracellular IL-17 production despite hypermethylation at $R O R C$ regions in $\mathrm{dcSSc}$ is that in our assay, DNA from total PBMCs due to small sample volumes of dcSSc patients and $\mathrm{HC}$ was taken to analyze methylation levels at RORC1, RORC2, FOXP3, STAT3, and STAT5A regions, but not from isolated T-cell subsets. Recently, it has been shown that RORC2 is differentially methylated in classic CD4+CD161-CCR6-IFN $\gamma+$ Th1 cells, and transiently in Th17/Th1 (CD4+CD161+CCR6+IL-17A+IFN $\gamma+)$ cells and nonclassic CD4+CD161+CCR6+IFN $\gamma+$ Th1 cells [57]. Thus, hypermethylation at $R O R C$ regions may result rather from other Th cell subpopulations, such as Th1 or Th2, than from the relatively small peripheral Th17 subpopulation. However, in our study, hypomethylation at CpGs within FOXP3 promoter regions goes ahead with inflammatory activity in dcSSc patients. FOXP3 promoter was not found to have repressive effects on Th1 or Th17 cells, which was interpreted that FOXP3 can be more widely and transiently expressed in Tregs as well as in activated T cells [55].

Novel therapeutic strategies targeting the IL-17 axis or IL-6 as an important proinflammatory cytokine inducing Th17 cells [49] have been suggested for the treatment of SSc patients. Our results also suggest a high plasticity of Tregs that is strongly associated with the Th17 phenotype. Future research directions may focus on stabilization of the Treg phenotype and on enhancing Treg functions, as our results revealed a proportional increase in $\mathrm{T}$ cells showing features of Tregs at the transcriptional and phenotypical level.

\section{Acknowledgment}

The study was supported by the IZKF grant Z-4/94 donated to Martina Prelog.

\section{Disclosure Statement}

There are no conflicts of interest for any author. 


\section{References}

1 Baraut J, Michel L, Verrecchia F, Farge D: Relationship between cytokine profiles and clinical outcomes in patients with systemic sclerosis. Autoimmun Rev 2010;10:65-73.

2 Kurzinski K, Torok KS: Cytokine profiles in localized scleroderma and relationship to clinical features. Cytokine 2011;55:157-164.

3 Kurasawa K, Hirose K, Sano H, Endo H, Shinkai H, Nawata Y, et al: Increased interleukin-17 production in patients with systemic sclerosis. Arthritis Rheum 2000;43:24552463.

4 Murata M, Fujimoto M, Matsushita T, Hamaguchi Y, Hasegawa M, Takehara K, et al: Clinical association of serum interleukin-17 levels in systemic sclerosis: is systemic sclerosis a Th17 disease? J Dermatol Sci 2008;50:240242.

5 Radstake TR, van Bon L, Broen J, Hussiani A, Hesselstrand R, Wuttge DM, et al: The pronounced Th17 profile in systemic sclerosis (SSc) together with intracellular expression of TGF $\beta$ and IFN $\gamma$ distinguishes SSc phenotypes. PLoS One 2009;4:e5903.

6 Deleuran B, Abraham DJ: Possible implication of the effector CD4+ T-cell subpopulation TH17 in the pathogenesis of systemic scleroderma. Nat Clin Pract Rheumatol 2007; 3:682-683.

7 Rodríguez-Reyna TS, Furuzawa-Carballeda J, Cabiedes J, Fajardo-Hermosillo LD, Martínez-Reyes C, Díaz-Zamudio M, et al: Th17 peripheral cells are increased in diffuse cutaneous systemic sclerosis compared with limited illness: a cross-sectional study. Rheumatol Int 2012;32:2653-2660.

8 Mathian A, Parizot C, Dorgham K, Trad S, Arnaud L, Larsen M, et al: Activated and resting regulatory $\mathrm{T}$ cell exhaustion concurs with high levels of interleukin-22 expression in systemic sclerosis lesions. Ann Rheum Dis 2012;71:1227-1234.

9 Antiga E, Quaglino P, Bellandi S, Volpi W, Del Bianco E, Comessatti A, et al: Regulatory $T$ cells in the skin lesions and blood of patients with systemic sclerosis and morphoea. Br J Dermatol 2010;162:1056-1063.

10 Levings MK, Bacchetta R, Schulz U, Roncarolo MG: The role of IL-10 and TGF-beta in the differentiation and effector function of $\mathrm{T}$ regulatory cells. Int Arch Allergy Immunol 2002; 129:263-276.

11 Veldman C, Nagel A, Hertl M: Type I regulatory $\mathrm{T}$ cells in autoimmunity and inflammatory diseases. Int Arch Allergy Immunol 2006;140:174-183.

12 Klein S, Kretz CC, Ruland V, Stumpf C, Haust M, Hartschuh W, et al: Reduction of regulatory $\mathrm{T}$ cells in skin lesions but not in peripheral blood of patients with systemic scleroderma. Ann Rheum Dis 2011;70:14751481.

13 Radstake TR, van Bon L, Broen J, Wenink M, Santegoets K, Deng Y, et al: Increased frequency and compromised function of T regu- latory cells in systemic sclerosis (SSc) is related to a diminished CD69 and TGF $\beta$ expression. PLoS One 2009;4:e5981.

14 Slobodin G, Ahmad MS, Rosner I, Peri R, Rozenbaum M, Kessel A, et al: Regulatory T cells $\left(\mathrm{CD}^{+} \mathrm{CD}_{25} 5^{\text {bright }} \mathrm{FoxP}^{+}\right)$expansion in systemic sclerosis correlates with disease activity and severity. Cell Immunol 2010;261: 77-80.

15 Giovannetti A, Rosato E, Renzi C, Maselli A, Gambardella L, Giammarioli AM, et al: Analyses of $\mathrm{T}$ cell phenotype and function reveal an altered $\mathrm{T}$ cell homeostasis in systemic sclerosis. Correlations with disease severity and phenotypes. Clin Immunol 2010;137:122133.

16 Yang X, Yang J, Xing X, Wan L, Li M: Increased frequency of Th17 cells in systemic sclerosis is related to disease activity and collagen overproduction. Arthritis Res Ther 2014;16:R4.

17 Zhou Y, Hou W, Xu K, Han D, Jiang C, Mou $\mathrm{K}$, et al: The elevated expression of Th17-related cytokines and receptors is associated with skin lesion severity in early systemic sclerosis. Hum Immunol 2015;76:22-29.

18 Liu M, Wu W, Sun X, Yang J, Xu J, Fu W, Li M: New insights into CD4+ T cell abnormalities in systemic sclerosis. Cytokine Growth Factor Rev 2016;28:31-36.

19 Yamamoto T: Chemokines and chemokine receptors in scleroderma. Int Arch Allergy Immunol 2006;140:345-356.

20 Khoury SJ: Th17 and Treg balance in systemic sclerosis. Clin Immunol 2011;139:231-232.

21 Lei W, Luo Y, Yan K, Zhao S, Li Y, Qiu X, et al: Abnormal DNA methylation in CD4+ T cells from patients with systemic lupus erythematosus, systemic sclerosis, and dermatomyositis. Scand J Rheumatol 2009;38:369374.

22 Jiang H, Xiao R, Lian X, Kanekura T, Luo Y, Yin Y, et al: Demethylation of TNFSF7 contributes to CD70 overexpression in CD4+ T cells from patients with systemic sclerosis. Clin Immunol 2012;143:39-44.

23 Selmi C, Feghali-Bostwick CA, Lleo A, Lombardi SA, De Santis M, Cavaciocchi E, et al: X chromosome gene methylation in peripheral lymphocytes from monozygotic twins discordant for scleroderma. Clin Exp Immunol 2012;169:253-262.

24 Altorok N, Almeshal N, Wang Y, Kahaleh B: Epigenetics, the holy grail in the pathogenesis of systemic sclerosis. Rheumatology (Oxford) 2015;54:1759-1770.

25 Wang YY, Wang Q, Sun XH, Liu RZ, Shu Y, Kanekura T, et al: DNA hypermethylation of the forkhead box protein 3 (FOXP3) promoter in CD4+ T cells of patients with systemic sclerosis. Br J Dermatol 2014;171:39-47.

26 van den Hoogen KD, Fransen J, Johnson SR, Baron M, Tyndall A, et al: 2013 classification criteria for systemic sclerosis: an American College of Rheumatology/European League against Rheumatism Collaborative initiative. Ann Rheum Dis 2013;72:1747-1755.

27 Muangchan C; Canadian Scleroderma Research Group, Baron M, Pope J: The 15\% rule in scleroderma: the frequency of severe organ complications in systemic sclerosis. A systematic review. J Rheumatol 2013;40:1545-1556.

28 Fenoglio D, Battaglia F, Parodi A, Stringara S, Negrini S, Panico N, et al: Alteration of Th17 and Treg cell subpopulations co-exist in patients affected with systemic sclerosis. Clin Immunol 2011;139:249-257.

29 Cosmi L, De Palma R, Santarlasci V, Maggi L, Capone M, Frosali F, et al: Human interleukin 17-producing cells originate from a CD161+CD4+ T cell precursor. J Exp Med 2008;205:1903-1916.

30 Brembilla NC, Montanari E, Truchetet ME, Raschi E, Meroni P, Chizzolini C: Th17 cells favor inflammatory responses while inhibiting type I collagen deposition by dermal fibroblasts: differential effects in healthy and systemic sclerosis fibroblasts. Arthritis Res Ther 2013;15:R151.

31 Duhen T, Geiger R, Jarrossay D, Lanzavecchia A, Sallusto F: Production of interleukin 22 but not interleukin 17 by a subset of human skinhoming memory T cells. Nat Immunol 2009; 10:857-863.

32 Trifari S, Kaplan CD, Tran EH, Crellin NK, Spits H: Identification of a human helper $\mathrm{T}$ cell population that has abundant production of interleukin 22 and is distinct from $\mathrm{T}(\mathrm{H})-17$, $\mathrm{T}(\mathrm{H}) 1$ and $\mathrm{T}(\mathrm{H}) 2$ cells. Nat Immunol 2009; 10:864-871.

33 Truchetet ME, Brembilla NC, Montanari E, Allanore Y, Chizzolini C: Increased frequency of circulating Th22 in addition to Th17 and Th2 lymphocytes in systemic sclerosis: association with interstitial lung disease. Arthritis Res Ther 2011;13:R166.

34 Singh SP, Zhang HH, Foley JF, Hedrick MN Farber JM: Human T cells that are able to produce IL-17 express the chemokine receptor CCR6. J Immunol 2008;180:214-221.

35 Ochoa E, Martin JE, Assasi S, Beretta L, Carreira $\mathrm{P}$, Guillén A, et al: Confirmation of CCR6 as a risk factor for anti-topoisomerase I antibodies in systemic sclerosis. Clin Exp Rheumatol 2015;33:S31-S35.

36 Gourh P, Arnett FC, Assassi S, Tan FK, Huang M, Diekman L, et al: Plasma cytokine profiles in systemic sclerosis: associations with autoantibody subsets and clinical manifestations. Arthritis Res Ther 2009;11:R147.

37 Peltonen J, Kähäri L, Jaakkola S, Kähäri VM, Varga J, Uitto J, et al: Evaluation of transforming growth factor beta and type I procollagen gene expression in fibrotic skin diseases by in situ hybridization. J Invest Dermatol 1990;94: 365-371.

38 Warrington KJ, Nair U, Carbone LD, Kang $\mathrm{AH}$, Postlethwaite AE: Characterisation of the immune response to type I collagen in scleroderma. Arthritis Res Ther 2006;8:R136. 
39 Sato S, Hasegawa M, Takehara K: Serum levels of interleukin- 6 and interleukin- 10 correlate with total skin thickness score in patients with systemic sclerosis. J Dermatol Sci 2001; 27:140-146.

40 Kucharz EJ, Brzezinska-Wcislo L, Kotulska A, Gasiorowska-Kielkowska W, Gozdzik J: Elevated serum level of interleukin-10 in patients with systemic sclerosis. Clin Rheumatol 1997; 16:638-639.

41 Mathes AL, Christmann RB, Stifano G, Affandi AJ, Radstake TR, Farina GA, et al: Global chemokine expression in systemic sclerosis (SSc): CCL19 expression correlates with vascular inflammation in SSc skin. Ann Rheum Dis 2014;73:1864-1872.

42 Miyara M, Yoshioka Y, Kitoh A, Shima T, Wing K, Niwa A, et al: Functional delineation and differentiation dynamics of human CD4+ T cells expressing the FoxP 3 transcription factor. Immunity 2009;30:899-911.

43 Papp G, Horvath IF, Barath S, Gyimesi E, Sipka S, Szodoray P, et al: Altered T-cell and regulatory cell repertoire in patients with diffuse cutaneous systemic sclerosis. Scand J Rheumatol 2011;40:205-210.

44 Osorio F, LeibundGut-Landmann S, Lochner M, Lahl K, Sparwasser T, Eberl G, et al: DC activated via dectin- 1 convert Treg into IL-17 producers. Eur J Immunol 2008;38:32743281.
45 Yang XO, Nurieva R, Martinez GJ, Kang HS, Chung Y, Pappu BP, et al: Molecular antagonism and plasticity of regulatory and inflammatory T cell programs. Immunity 2008;29: 44-56.

46 Koenen HJ, Smeets RL, Vink PM, van Rijssen E, Boots AM, Joosten I: Human CD25highFoxp3pos regulatory T cells differentiate into IL-17-producing cells. Blood 2008; 112:2340-2352.

47 Lim HW, Lee J, Hillsamer P, Kim CH: Human Th17 cells share major trafficking receptors with both polarized effector $\mathrm{T}$ cells and FOXP3+ regulatory T cells. J Immunol 2008; 180:122-129.

48 Klein S, Kretz CC, Krammer PH, Kuhn A: CD127(low/-) and FoxP3(+) expression levels characterize different regulatory $\mathrm{T}$-cell populations in human peripheral blood. J Invest Dermatol 2010;130:492-499.

49 Zhou X, Bailey-Bucktrout S, Jeker LT, Bluestone JA: Plasticity of CD4(+) FoxP3(+) T cells. Curr Opin Immunol 2009;21:281-285.

50 Bovenschen HJ, van de Kerkhof PC, van Erp PE, Woestenenk R, Joosten I, Koenen HJ: Foxp3+ regulatory $\mathrm{T}$ cells of psoriasis patients easily differentiate into IL-17A-producing cells and are found in lesional skin. J Invest Dermatol 2011;131:1853-1860.

51 Braitch M, Harikrishnan S, Robins RA, Nichols C, Fahey AJ, Showe L, et al: Glucocorticoids increase CD4CD25 cell percentage and Foxp3 expression in patients with multiple sclerosis. Acta Neurol Scand 2009;119:239245.
52 Chen X, Oppenheim JJ, Winkler-Pickett RT, Ortaldo JR, Howard OM: Glucocorticoid amplifies IL-2-dependent expansion of functional FoxP3(+)CD4(+)CD25(+) T regulatory cells in vivo and enhances their capacity to suppress EAE. Eur J Immunol 2006;36:21392149.

53 Olewicz-Gawlik A, Danczak-Pazdrowska A, Kuznar-Kaminska B, Gornowicz-Porowska J, Katulska K, Trzybulska D, et al: Interleukin-17 and interleukin-23: importance in the pathogenesis of lung impairment in patients with systemic sclerosis. Int J Rheum Dis 2014; 17:664-670.

54 Yan JW, Wang YJ, Peng WJ, Tao JH, Wan YN, Li BZ, et al: Therapeutic potential of interleukin-17 in inflammation and autoimmune diseases. Expert Opin Ther Targets 2014;18:29-41.

55 Kumar P, Subramaniyam G: Molecular underpinnings of Th17 immune-regulation and their implications in autoimmune diabetes. Cytokine 2015;17:366-376.

56 Liu H, Cao AT, Feng T, Li Q, Zhang W, Yao $S$, et al: TGF- $\beta$ converts Th1 cells into Th17 cells through stimulation of Runx1 expression. Eur J Immunol 2015;45:1010-1018.

57 Mazzoni A, Santerlasci V, Maggi L, Capone M, Rossi MC, Querci V, et al: Demethylation of the RORC2 and IL17A in human CD4+ T lymphocytes defines Th17 origin of nonclassic Th1 cells. J Immunol 2015;194:3116-3126. 